\title{
A retrospective study of serious adverse drug reactions and associated risk factors in a tertiary care hospital
}

\author{
Smita Shenoy ${ }^{1}$, Mohit Gupta ${ }^{2}$, Sadhana Holla ${ }^{1}$, Madhurima Home ${ }^{3}$, \\ Harish Thanusubramanian ${ }^{4}$
}

\author{
${ }^{1}$ Department of Pharmacology, Kasturba Medical College, Manipal, Manipal Academy of Higher Education, Udupi, \\ Karnataka, India \\ ${ }^{2}$ Department of Surgery, Jagadguru Sri Shivarathreeshwara Medical College, Mysuru, Karnataka, India \\ ${ }^{3}$ Mayo Clinic, 5777 East Mayo Boulevard, Phoenix, USA \\ ${ }^{4}$ Pfizer India Ltd, Mumbai, Maharashtra, India
}

Received: 24 September 2019

Revised: 13 November 2019

Accepted: 21 November 2019

*Correspondence:
Dr. Sadhana Holla,
Email: sadhana.holla@manipal.edu

Copyright: () the author(s), publisher and licensee Medip Academy. This is an open-access article distributed under the terms of the Creative Commons Attribution Non-Commercial License, which permits unrestricted non-commercial use, distribution, and reproduction in any medium, provided the original work is properly cited.

\begin{abstract}
Background: Serious adverse drug reactions (ADRs) cause physical, psychological and economic harm to patients and society. This study was undertaken to understand serious ADRs in a tertiary care hospital and risk factors associated with it.

Methods: The serious adverse reactions that occurred over a one-year period were assessed. The serious adverse drug reactions, action taken, outcome, predictability, suspect drug, causality, patient demographics and risk factors for the reaction was collected. Chi-square test was applied for observing relationships of predisposing factors for serious ADRs.

Results: Out of a total of 984 reported adverse drug reactions, 94 (9.55\%) were serious. Hematological disorders $(41.05 \%)$ were the common serious ADRs followed by electrolyte disturbances $(18.94 \%)$. Anticancer agents were the suspect drugs for majority of serious ADRs. Serious ADRs contributed to $39(0.05 \%)$ admissions in the hospital. Recovery occurred in $97.87 \%$ of the patients. The causality was possible in $91.48 \%(\mathrm{n}=86)$ and probable in $8.51 \%$ $(n=8)$ of the serious adverse drug reactions. Males, patients even with a single concomitant disease and those with more than 2 concomitant medications were at increased risk $(\mathrm{p}<0.05)$ for developing serious ADRs.

Conclusions: Serious ADRs are a significant problem in health care. Measures should be taken to detect and treat them at the earliest to reduce suffering of the patient.
\end{abstract}

Keywords: Cancer, Hematological, Causality, Predictability

\section{INTRODUCTION}

Drugs save life but they can also cause adverse drug reactions (ADRs). They place an economic burden on the patients and the health care sector. A lot of hospital resources and manpower have to be put in managing the same. If the ADR results in death, hospitalization, increase in duration of stay, disability or is life threatening, it is a serious ADR. ${ }^{1}$ Serious ADRs resulted in $3.1 \%$ to $6.2 \%$ of hospital admissions. ${ }^{2}$ In emergency department, ADRs of various severity were responsible for $2.5 \%$ of all visits, of which $16.7 \%$ required hospitalization. ${ }^{3}$ A study in a secondary care hospital in India reported an incidence of $9.8 \%$ for adverse drug reactions, $3.4 \%$ of which resulted in hospital admissions. ${ }^{4}$

To reduce these figures and to minimize the patient suffering because of serious ADRs, it is important to 
recognize them early, establish the causal relationship with drug, identify risk factors and implement measures to treat and prevent the adverse reactions. Hence, the serious ADRs in the hospital were studied along with risk factors associated with it. The objective was to identify the suspect drug, causality, action taken, outcome, predictability, and hospital admissions due to the reactions.

\section{METHODS}

The study was carried out following approval by the Institutional Ethics Committee. The one year data was collected from Medical records section of Kasturba hospital, Manipal and Department of Pharmacology which monitors adverse drug reactions. This was a retrospective study. The study period was January 2014 to December 2014. The demographic data that includes age, sex, date of diagnosis of disease, serious adverse drug reaction, action taken and outcome of reaction any suspect drug details, any other concomitant medication being taken, any coexisting disease, number of serious ADRs calculated for the specified period was collected.

Anatomical therapeutic and chemical (ATC) classification system was used for drug categories. ${ }^{5}$ Causality of the adverse reaction was assessed using WHO-UMC system for standardized case causality assessment. $^{6}$

The total number of hospital admissions due to serious ADRs was calculated after obtaining total number of admissions for the year. Predictability was based on Rawlins and Thompson system. ${ }^{7}$ Risk factors, if any, for the serious adverse reactions were identified.

\section{Statistical analysis}

Mean and standard deviation (mean \pm SD) was used for variables with normal distribution while those without normal distribution were summarized using the median, the lower (Q1) quartile, and upper (Q3) quartile. Chisquare test was applied for observing relationships of predisposing factors for serious ADRs.

\section{RESULTS}

Overall, 984 adverse drug reactions were reported. Serious ADRs were 94 (9.55\%). The median duration (days) of disease for which suspect drug was prescribed was $150(60,170)$.

\section{Gender and age}

About $48.94 \% \quad(n=46)$ were males and $51.06 \% \quad(n=48)$ were females. The age $($ mean $\pm S D)$ of patients with serious ADRs was $48.63 \pm 15.59$ years. The age (mean \pm SD) of males and females who developed serious ADRs was $47.68 \pm 16.56$ years and $49.56 \pm 14.70$ years, respectively.

\section{Criteria for serious adverse drug reactions}

About $41.49 \% \quad(n=39)$ of the serious ADRs $(n=94)$ resulted in hospitalization, $41.49 \%(n=39)$ in prolonged hospitalization, $17.02 \%(\mathrm{n}=16)$ were life threatening.

\section{Hospital admissions}

The total number of hospital admissions was 75,219. Of this, 39 admissions $(0.05 \%)$ were due to serious adverse drug reactions. The median duration of hospital stay due to serious adverse drug reaction (in days) was $7(4,11)$.

\section{Suspect drugs and serious adverse drug reactions observed}

Hematological disorders (41.05\%) were the common serious ADRs followed by electrolyte disturbances (18.94\%). Anticancer drugs constituted the majority of serious adverse drug reactions (Table 1).

Table 1: Suspect drugs and serious ADRs.

\begin{tabular}{|lll|}
\hline $\begin{array}{l}\text { Serious adverse drug reactions } \\
\text { Haematological disorders }(\mathbf{n = 3 9})\end{array}$ & Number & Suspect drug (no. of reactions) \\
\hline Leucopenia & 15 & $\begin{array}{l}\text { Cyclophosphamide (7), cisplatin (4), docetaxel (1) carboplatin } \\
(1), \text { mycophenolate mofetil (1), tacrolimus (1) }\end{array}$ \\
\hline Febrile neutropenia & 12 & $\begin{array}{l}\text { Cyclophosphamide (4), doxorubicin (2), paclitaxel (2), docetaxel } \\
(1), \text { cisplatin (1), vinblastine (1) } \\
\text { 5-fluorouracil (1) }\end{array}$ \\
\hline Thrombocytopenia & 07 & $\begin{array}{l}\text { Carboplatin (2), cisplatin (2), cyclophosphamide (1) } \\
\text { melphalan (1), lenalidomide (1) }\end{array}$ \\
\hline Anaemia & 03 & zidovudine \\
\hline Bone marrow suppression & 02 & Azathioprine, cyclophosphamide \\
\hline Electrolyte abnormalities $(\mathbf{n = 1 8})$ & & Furosemide (5), torsemide (3), hydrochlorothiazide (3) \\
\hline Hyponatraemia & 11 & Budesonide (2), cisplatin (1), furosemide (1), prednisolone (1) \\
\hline Hypokalaemia & 05 & Enalapril, potassium chloride \\
\hline Hyperkalaemia & 02 &
\end{tabular}




\begin{tabular}{|c|c|c|}
\hline Serious adverse drug reactions & Number & Suspect drug (no. of reactions) \\
\hline \multicolumn{3}{|l|}{ Hypersensitivity reactions $(n=13)$} \\
\hline Stevens - Johnson syndrome & 08 & $\begin{array}{l}\text { Methotrexate, aceclofenac, diclofenac, nimesulide, cefexime, } \\
\text { nevirapine, phenobarbitone, phenytoin }\end{array}$ \\
\hline *DRESS syndrome & 02 & Dapsone, phenytoin \\
\hline Anaphylactic shock & 1 & Ceftriaxone \\
\hline Anaphlylactoid reaction & 1 & Human albumin \\
\hline Erythema multiforme & 1 & Phenytoin \\
\hline \multicolumn{3}{|l|}{ Liver abnormalities $(\mathrm{n}=\mathbf{1 0})$} \\
\hline Hepatitis & 10 & Chlorpromazine (1), pyrazinamide (8), zidovudine (1) \\
\hline \multicolumn{3}{|l|}{ Renal abnormalities $(n=04)$} \\
\hline Renal failure & 02 & Ibuprofen, tenofovir \\
\hline Nephritis & 01 & Amikacin \\
\hline Nephropathy & 01 & Diclofenac \\
\hline \multicolumn{3}{|l|}{ Others $(n=10)$} \\
\hline Seizures & 02 & Chlorpromazine, clozapine \\
\hline Hypoglycaemia & 01 & Glimepiride \\
\hline Glaucoma & 01 & Methylprednisolone \\
\hline Pancreatitis & 01 & Stavudine \\
\hline Pleural effusion & 01 & Dasatinib \\
\hline Hypotension & 01 & Indapamide \\
\hline Rhabdomylosis & 01 & Atorvastatin \\
\hline Venous thrombosis & 01 & Ethinyl estradiol \\
\hline Diarrhoea & 01 & Capacitabine \\
\hline
\end{tabular}

*Drug Rash with Eosinophilia and Systemic Symptoms.

\section{ATC classification of suspect drugs}

The suspect drugs were classified as per ATC classification. Antineoplastic and immunomodulating agents were the major class (Table 2).

Table 2: ATC classification of suspect drugs.

\begin{tabular}{|ll|}
\hline $\begin{array}{l}\text { L=Antineoplastic and immunomodulating } \\
\text { agents }\end{array}$ & 16 \\
\hline J=Antiinfectives for systemic use & 09 \\
\hline C=Cardiovascular system & 06 \\
\hline N=Nervous system & 08 \\
\hline $\begin{array}{l}\text { H=Systemic hormonal preparations, } \\
\text { excluding sex hormones and insulin }\end{array}$ & 03 \\
\hline G=Genitourinary system and sex hormones & 01 \\
\hline A=Alimentary tract and metabolism & 01 \\
\hline B=Blood and blood forming organs & 01 \\
\hline V=Various & 01 \\
\hline
\end{tabular}

\section{Action taken for the serious adverse drug reactions}

Suspect drug was either stopped or continued with/ without specific treatment for almost equal number of ADRs (Table 3).

\section{Outcome of the serious adverse drug reactions}

Recovery was seen in $(97.87 \%)$ of the patients while others were recovering when data was recorded.
Table 3: Action taken for adverse drug reactions.

\begin{tabular}{|l|l|}
\hline Action taken & $\begin{array}{l}\text { Number of } \\
\text { ADRs (\%) }\end{array}$ \\
\hline $\begin{array}{l}\text { Drug not stopped but specific } \\
\text { treatment given }\end{array}$ & $35(37.23)$ \\
\hline $\begin{array}{l}\text { Drug stopped and specific treatment } \\
\text { given }\end{array}$ & $30(31.91)$ \\
\hline $\begin{array}{l}\text { Drug stopped but no specific } \\
\text { treatment given }\end{array}$ & $18(19.14)$ \\
\hline $\begin{array}{l}\text { No action - drug continued, no } \\
\text { specific treatment given }\end{array}$ & $08(8.51)$ \\
\hline $\begin{array}{l}\text { Dose of drug reduced and specific } \\
\text { treatment given }\end{array}$ & $02(2.13)$ \\
\hline $\begin{array}{l}\text { Dose of drug reduced, no specific } \\
\text { treatment given }\end{array}$ & $01(1.06)$ \\
\hline
\end{tabular}

\section{Causality of serious adverse drug reactions}

This was assessed using WHO causality assessment scale. The causality was possible in $91.48 \% \quad(n=86)$ and probable in $8.51 \%(\mathrm{n}=8)$.

\section{Predictability of serious ADRs}

Of the 94 serious ADRs, 81 (88.42\%) were predictable and $13(11.57 \%)$ were non-predictable.

\section{Coexisting disease and concomitant medications}

Patients were receiving more than one medication either for the primary disease or coexisting disease. The primary 
disease which required more than one drug were cancer, bronchial asthma, tuberculosis, AIDS, leprosy, hypertension, congestive cardiac failure and road traffic accident. The coexisting diseases were hypertension, ischemic heart disease, diabetes mellitus, bronchial asthma, HIV and epilepsy. Concomitant medications were anticancer drugs (gemcitabine, rituximab, cisplatin, vincristine, etoposide), antimicrobials, steroids, analgesics, antidiabetic agents, antiasthma drugs and drugs for cardiovascular disorders.

\section{Suspect drug and indication}

The indications for the suspect drugs ranged from cancer, cardiovascular diseases, respiratory disorders, renal diseases, electrolyte imbalance, infections, pain relief, metabolic disorders, psychiatric illness, joint diseases, fever, hypoalbuminemia, seizures, irregular menstrual cycles etc. The route of administration varied from oral, intravenous, intramuscular and inhalation. The doses of drugs were as per treatment guidelines.

\section{Risk factors for serious adverse drug reactions}

Chi square test was used. Patients with serious ADRs were compared with those who were on the suspect drugs but had either no ADRs or nonserious ADRs. Males, patients even with a single concomitant disease and those with more than 2 concomitant medications were at increased risk $(\mathrm{p}<0.05)$ for developing serious ADRs (Table 4).

Table 4: Risk factors for serious adverse drug reactions.

\begin{tabular}{|lcl|}
\hline $\begin{array}{l}\text { Variable } \\
\text { Gender }\end{array}$ & Odds ratio $(95 \%$ CI) & P value \\
\hline Male & (reference) \\
\hline Female & $0.63(0.40-0.98)$ & 0.042 \\
\hline No of concomitant diseases \\
\hline 1 & (reference) \\
\hline$>1$ & $0.08(0.04-0.13)$ \\
\hline Number of concomitant medications \\
\hline$\leq 2$ & (reference) \\
\hline$>2$ & 2.09 $(1.16-3.70)$ \\
\hline
\end{tabular}

\section{DISCUSSION}

Our study assessed serious ADRs occurring in a tertiary care hospital in one year. Serious ADRs constituted 9.55\% of total ADRs that occurred during this period. This is higher than $5.42 \%$ of serious ADRs reported in another study. ${ }^{8}$ This could be due to the fact that our study was for one-year duration and recorded serious ADRs across all departments unlike other studies which were conducted for short duration or in a particular department. ${ }^{9}$ Studies conducted in India have put the number of hospital admissions due to ADRs at $0.12 \%$ to
$0.7 \%$ of all hospital admissions. ${ }^{10,11}$ The numbers reported are lower compared to the west- $3.2-6.5 \%$ in the USA - on account of poor reporting of ADRs in India. ${ }^{12}$ Hospital admissions was lower $(0.05 \%)$ in our study as compared to another study in India which had $0.7 \%$ ADR related admissions. ${ }^{11}$ In another study, $73 \%$ of ADRs caused an increase in duration of stay in the hospital which is more than $41.49 \%$ in our study. ${ }^{13}$

Rawlins and Thompson described adverse effects as type A and type B. ${ }^{7}$ A majority of serious ADRs in this study were type A (predictable) as they are documented in literature and dose dependent. The remaining reactions were type B as they cannot be predicted. They were the hypersensitivity reactions which can be immediate type, type II or type III reactions.

Adverse reaction can occur with any class of drugs and can affect any system. In our study, anticancer drugs were the most common suspect drug. The immediate common effect of most of the anticancer drugs is nausea and vomiting due to gastric irritation and stimulation of chemoreceptor trigger zone. Some of the ADRs due to anticancer drugs results from their pharmacological action, which affects not only cancer cells but also the normal cells. ${ }^{14}$

Antimicrobials are used commonly for treatment and prophylaxis of infections. They have different mechanism of action and adverse effects. Most of the patients admitted in hospitals receive antimicrobials which results in $20-50 \%$ of drug related cost. About $70 \%$ of patients in intensive care are prescribed antimicrobials either as empiric or definitive treatment. The cost of treatment due to antibiotic use includes cost of the antimicrobial and ADRs to it. ${ }^{15}$ Diuretic use is frequently associated with side effects like electrolyte disturbances, hypotension, etc which can result in hospitalization. The patients should be monitored to detect and treat the ADR at the earliest. ${ }^{16}$

Age, alcohol, gender, race, pregnancy, renal impairment, hepatic dysfunction, coexisting disease, concomitant mediations, genetics, etc. also contribute to development of ADRs. ${ }^{17}$ Advancing age increases co-morbidities, polypharmacy, alters pharmacokinetics and pharmacodynamics. ${ }^{17}$ In elderly patients, comorbidities results in use of more than one medication. Also, the change in pharmacokinetics and pharmacodynamics could increase the risk of ADRs. Studies have shown that polypharmacy increases risk for ADRs and drug interactions. ${ }^{18,19}$ In our study, gender was a risk factor as females were more prone to serious ADRs. This could be due to physiological, pharmacological, and hormonal factors. ${ }^{20}$ All these factors should be kept in mind while prescribing so as to minimize adverse effects wherever possible. ${ }^{17}$

For a majority of reactions, the suspect drug was withdrawn with or without specific treatment in our study. In almost an equal number of serious ADRs, the suspect drug was continued which indicates that the benefit 
associated with the use of such drugs outweighed the risk due to their adverse effects. A majority of patients recovered - this could be due to early identification of the adverse drug reaction and proper management of ADRs. Immediate measure is crucial for reactions like anaphylactic shock. If the medicine is critical to the patient, the benefit and risk from use of such drugs should be considered. The need for the drug, availability of alternatives, the treatment of ADR can guide the decision. A decrease in dose can also resolve the reaction. Otherwise, symptomatic treatment should be provided while the drug is continued. ${ }^{1}$ If patient is on multiple drugs, the most likely suspect drug can be withdrawn first and patient observed for resolution of reaction. ${ }^{1}$

The management of serious ADRs has a financial implication for the patient and society. Thus, while determining success or failure of treatment, financial impact should be assessed. $^{21}$

The limitation of the study was that it could not capture the actual figures of patients on suspect drugs in the hospital due to lack of electronic record.

To conclude, a drug produces both beneficial and harmful effects. Yet, they are prescribed as a benefit from their use is more than risk. Serious ADRs pose a problem to the quality of life of the patient. Early recognition and management of the reactions will add to the wellbeing of the patient and help to decrease cost of healthcare.

\section{Funding: No funding sources}

Conflict of interest: None declared

Ethical approval: The study was approved by the Institutional Ethics Committee

\section{REFERENCES}

1. Edwards IR, Aronson JK. Adverse drug reactions: Definitions, diagnosis, and management. Lancet. 2000;356:1255-9.

2. Lazarou J, Pomeranz BH, Corey PN. Incidence of ADRs in Hospitalized Patients -a metaanalysis of prospective studies JAMA. 1998;279(15):1200-5.

3. Budnitz DS, Pollock DA, Weidenbach KN, Mendelsohn AB, Schroeder TJ, Annest JL. National surveillance of emergency department visits for outpatient adverse drug events. JAMA. 2006;296(15):1858-66.

4. Arulmani R, Rajendran SD, Suresh B. Adverse drug reaction monitoring in a secondary care hospital in South India. Br J Clin Pharmacol. 2008;65:210-6.

5. WHO Collaborating Centre for Drug Statistics Methodology and Norwegian Institute of Public Health. Guidelines for ATC classification and DDD assignment 2013. Available at: https://www. whocc.no/filearchive/publications/1_2013guidelines. pdf. Accessed on 14 September 2014.
6. The use of the WHO-UMC system for standardised case causality assessment. Available at: http://www.WHOUMC.org/graphics/4409.pdf. Accessed on 10 August 2014.

7. Rawlins MD. Thompson JW. Pathogenesis of adverse drug reactions. In: Davies DM, editor. Textbook of adverse drug reactions. Oxford: Oxford University Press; 1977: 10.

8. Vora MB, Trivedi HR, Shah BK, Tripathi CB. Adverse drug reactions in inpatients of internal medicine wards at a tertiary care hospital: A prospective cohort study. J Pharmacol Pharmacother. 2011;2(1):21-5.

9. Sharma H, Aqil M, Imam F, Alam MS, Kapur P, Pillai KK. A pharmacovigilance study in the department of medicine of a university teaching hospital. Pharm Pract (Granada). 2007;5(1):46-9.

10. Jamunarani R, Priya M. Analysis of adverse drug reaction related hospital admissions and common challenges encountered in ADR reporting in a tertiary care teaching hospital. Asian J Pharm Clin Res. 2014;7:141-3.

11. Ramesh M, Pandit J, Parthasarathi G. Adverse drug reactions in a south Indian hospital--their severity and cost involved. Pharmacoepidemiol Drug Saf. 2003;12(8):687-92.

12. Camargo AL, Cardoso Ferreira MB, Heineck I. Adverse drug reactions: a cohort study in internal medicine units at a university hospital. Eur J Clin Pharmacol. 2006;62:143-9.

13. Raut AL, Patel P, Patel C, Pawa A. Preventability, Predictability and Seriousness of Adverse Drug Reactions Amongst Medicine Inpatients in a Teaching Hospital: A Prospective Observational Study. Int J Pharm Chem Sc. 2012;1(3):1293-9.

14. Prasad A, Datta PP, Bhattacharya J, Pattanayak C, Chauhan AS, et al. Pattern of Adverse Drug Reactions Due to Cancer Chemotherapy in a Tertiary Care Teaching Hospital in Eastern India. J Pharmacovigilance. 2013;1:107.

15. Shamna M, Dilip C, Ajmal M, Linu Mohan P, Shinu $\mathrm{C}$, Jafer CP, et al. A prospective study on Adverse Drug Reactions of antibiotics in a tertiary care hospital. Saudi Pharm J. 2014;22:303-8.

16. Domenic AS. Diuretic-Related Side Effects: Development and Treatment. The J Clin Hypertension. 2004;6(9):532-40.

17. Muaed JA. Factors affecting the development of adverse drug reactions. Saudi Pharma J. 2014;22(2):83-94.

18. Gandhi TK, Weingart SN, Borus J, Seger AC, Peterson J, Burdick E, et al. Adverse drug events in ambulatory care. N Engl J Med. 2003;348:1556-64.

19. Zhang M, Holman CDJ, Price SD, Sanfilippo FM, Preen DB, Bulsara MK. Comorbidity and repeat admission to hospital for adverse drug reactions in older adults: retrospective cohort study. BMJ. 2008;337:2752. 
20. Rademaker M. Do women have more adverse drug reactions? Am J Clin Dermatol. 2006;2:349-51.

21. Schlienger RG, Oh PI, Knowles SR, Shear NH. Quantifying the costs of serious adverse drug reactions to antiepileptic drugs. Epilepsia. 1998;39(7):27-32.
Cite this article as: Shenoy S, Gupta M, Holla S, Home M, Thanusubramanian $\mathrm{H}$. A retrospective study of serious adverse drug reactions and associated risk factors in a tertiary care hospital. Int $\mathbf{J}$ Basic Clin Pharmacol 2020;9:101-6. 